\title{
BIRD-ECTOPARASITE INTERACTIONS, NEST HUMIDITY, AND ECTOPARASITE COMMUNITY STRUCTURE
}

\author{
Philipp Heeb, ${ }^{1}$ Mathias Kölliker, And Heinz Richner \\ Zoology Department, University of Bern, Centre for Behaviour and Evolution, CH-3032 Hinterkappelen, Switzerland
}

\begin{abstract}
Host nests are the key habitat for ectoparasite species that live and reproduce within the nest material. Nest properties can influence host and parasite reproductive success, and therefore the outcome of host-parasite interactions, as well as the composition of parasite communities. Previous correlational results suggested that nest humidity may increase the negative effect of fleas on Great Tit (Parus major) reproductive success. Since the causality of the relationship was unknown, we simultaneously manipulated both hen flea (Ceratophyllus gallinae) infestation and nest humidity in order to investigate: (1) the effect of flea infestation on nest humidity, (2) the effect of nest humidity on the prevalence of flea infestations, (3) the effect of nest humidity on adult flea survival and reproduction, (4) the interaction between flea infestations and nest humidity on Great Tit reproductive performance, and (5) the effect of both factors on secondary infestations by ectoparasitic Protocalliphora flies. The present study provides the first example of an ectoparasite acting as a physical ecosystem engineer where nest humidity increased as a result of flea infestations. In experimentally uninfested nests, infestation of hosts by immigrant fleas was more frequent in nests with reduced humidity. In experimentally infested nests, manipulation of humidity did not significantly affect the number of adult fleas or larvae. Hen flea infestation reduced Great Tit nestling body mass, tarsus length, and wing length, as well as the number of young fledged. The detrimental effect of the fleas on Great Tit reproduction was not altered by our modifications of nest humidity. The effect of fleas on nestling growth parameters and the number young fledged did not vary significantly with the seasonal decrease in reproductive performance of the birds, or with the number of young in the brood. The prevalence of secondary infestations by Protocalliphora was higher in nests with reduced humidity, and in nests experimentally infested with fleas. The numbers of Protocalliphora pupae were lower in flea-infested nests. This study provides the first experimental evidence that an abiotic factor within nests can affect ectoparasite infracommunity structure. It also provides the first evidence for an interspecific association between two ectoparasite species.

Key words: blow flies; Ceratophyllus gallinae; ecosystem engineering; ectoparasite; flea parasitism; Great Tit (Parus major); hen flea; nest cavity; nest humidity; Parus major; Protocalliphora.
\end{abstract}

\section{INTRODUCTION}

Natural selection favors parasites that maximize their rates of reproduction and transmission to new hosts (Bull 1994, Read 1994). Theoretical models assume, and some empirical evidence suggests, the existence of a correlation between a parasite's reproductive rate and its effect on host fitness (Ebert 1994, 1998, Lipsitch and Moxon 1997). Given the negative impact of parasites on host fitness (Brown and Brown 1986, Møller et al. 1990, Lehmann 1993, Møller 1997), there will be selection on hosts to avoid parasite infestations or keep parasite populations at low levels (Behnke et al. 1992, Goater and Holmes 1997). Recent models have shown that the structure and dynamics of parasite populations are important components of parasite virulence (Frank 1991, 1996). Thus, to understand the coevolutionary interactions between hosts and parasites, it is important to establish the factors that determine par-

Manuscript received 8 September 1998; revised 18 February 1999; accepted 3 March 1999.

${ }^{1}$ E-mail: philipp.heeb@esh.unibe.ch asite fitness and virulence (Lee and Clayton 1995, Ebert and Herre 1996, Ebert 1998).

In contrast to endoparasites that live in intimate contact with their host, ectoparasites are characterized by free-living stages where direct contact with the host ranges from the intermittent feeding of fleas to the prolonged attachment of ticks (Lehane 1991, Wakelin 1996). Nesting cavities of birds and mammals host a distinctive and varied ectoparasitic fauna where the nest material provides the key microhabitat in which free-ranging ectoparasites find refuge and reproduce (Rothschild and Clay 1952, Marshall 1981, 1987). Cavity-nesting hosts will often face ectoparasites during reproduction. In response, they have evolved behavioral, physiological, and immunological strategies to reduce the effect of parasites (Møller and Erritzøe 1996, Hart 1997, Heeb et al. 1998). When detecting the presence of ectoparasites in their nests, hosts can avoid parasite contact by changing nest sites (Christe et al. 1994, Oppliger et al. 1994, Butler and Roper 1996). Alternatively, birds can remove old nest material prior to nest building and thus reduce ectoparasite 
loads (Pacejka et al. 1998). Some birds include green plant materials or feathers in their nests which reduce the fitness of ectoparasites (Clark 1990, Winkler 1993, Dumbacher and Pruett-Jones 1996). Modifications of nest properties by the hosts will thus exert selection pressures on ectoparasites through a reduction in their survival and reproduction.

Several ectoparasite species often infect the same nest (Marshall 1981, Johnson and Albrecht 1993, Eeva et al. 1994, Lee and Clayton 1995), and host responses against one parasite could affect the fitness of other ectoparasites and modify ectoparasite communities. Given the large number of factors involved in hostparasite interactions, experimental parasite infestations are required to identify interspecific interactions among parasites, and the factors shaping parasite communities within host species (Simberloff and Moore 1997, Poulin 1998).

The hen flea (Ceratophyllus gallinae) is a common ectoparasite of cavity-nesting birds in the Western Palearctic (Harper et al. 1992, Tripet and Richner 1997a). Such birds are also frequently infested by blow flies of the genus Protocalliphora (Diptera: Calliphoridae) (Rothschild and Clay 1952, Marshall 1981, Eeva et al. 1994, Hurtrez-Boussès et al. 1997). Both types of ectoparasites have been shown to affect bird reproductive performance. Experimental infestations in Great Tit, Parus major, nests by hen fleas reduced the growth of nestlings, and the number of young fledged (Richner et al. 1993). Young Blue Tits (Parus caeruleus) growing in nests with reduced numbers of Protocalliphora larvae had longer tarsi and heavier body mass than nestlings in unmanipulated nests (Hurtrez-Boussès et al. 1997). A recent experiment tested for the presence of Great Tit-induced responses against hen fleas (Heeb et al. 1998). When raising their young in flea-infested nests, Great Tits exposed to fleas during egg laying raised young of greater body mass with higher recruitment rates the following year than Great Tits that were not exposed to fleas during egg laying. Data from that study revealed a strong negative correlation between mean nestling mass and nest humidity (Fig. 1). This relationship did not depend on the number of fleas in the nests, suggesting that nest humidity is somehow associated with the harmful effects of fleas on nestling growth.

In an earlier study (Heeb et al. 1996), we showed that fresh mass of Great Tits nests at fledging was positively correlated with both the number of adult fleas and their larvae, suggesting that density-dependent mechanisms among fleas could be an important component of flea population dynamics. An experiment with Blue Tit nests infested with different numbers of founders, further suggested that competition among larvae was the main process behind the density-dependent patterns observed (Tripet and Richner 1999). We also showed that the presence of fleas in Great Tit nests led to an increase in nest fresh mass. However, it was not

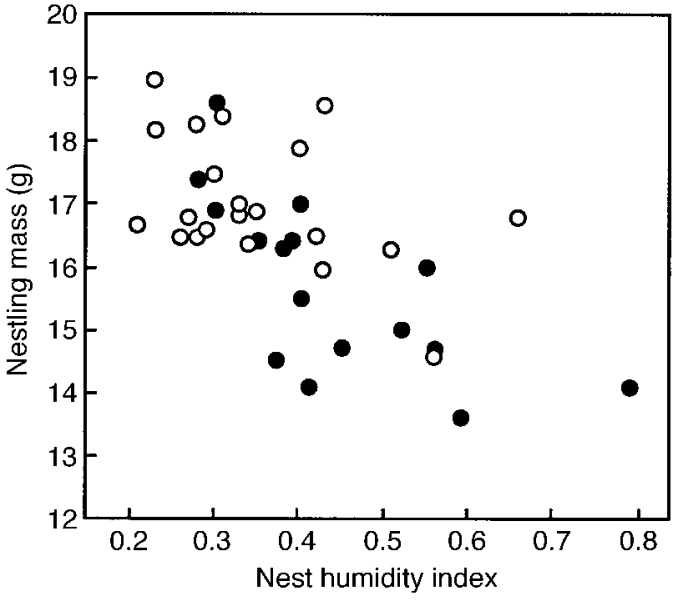

FIG. 1. Nestling mass in relation to nest humidity. Symbols are brood means and indicate whether Great Tit parents were exposed (open circles) or not (solid circles) to fleas during egg laying. Birds in both groups incubated the eggs, and raised their young in flea-infested nests. Nest humidity index is the total mass of water in the nest divided by nest dry mass. Nestling mass was negatively correlated with nest humidity $\left(F_{1,33}=15.43, P=0.0003\right)$ but was not correlated with the number of adult fleas $\left(F_{1.33}=0.09, P=0.76\right)$. Nestling mass was higher in nests of birds exposed to fleas during egg laying $\left(F_{1,33}=6.17, P=0.018\right)$.

determined whether the changes in nest mass were due to an increase in nest size or humidity (Heeb et al. 1996). An understanding of the relationship between nest humidity and the harmful effect of hen fleas on Great Tit reproduction (as shown in Fig. 1) will shed light on the mechanisms shaping interactions in this host-parasite system.

In a $2 \times 2$ factorial design, we simultaneously manipulated nest humidity and flea infestations to investigate; (1) the existence of a causal relationship between flea infestations and nest humidity, (2) the effect of nest humidity on the prevalence of flea infestations, (3) the effect of nest humidity on adult flea survival and reproduction, (4) whether differences in nest humidity altered the effect of hen fleas on Great Tit reproductive performance, and (5) the effects of flea infestations and nest humidity on the prevalence and intensity of Protocalliphora infestations.

\section{Methods}

\section{Study area and general procedures}

This study was carried out in the Bremgarten forest near the city of Bern, Switzerland $\left(46^{\circ} 57^{\prime} \mathrm{N}, 7^{\circ} 28^{\prime} \mathrm{E}\right)$. The forest has little undergrowth and is mainly composed of beech and pine, interspersed with a few oaks and hornbeams. Nest boxes were put up in 1991, and have been used by Great Tits since the breeding season of 1992. They consist of an outer plastic cover and an inner wooden box of $12.5 \times 12.5 \mathrm{~cm}$ with a height of $21 \mathrm{~cm}$ from the bottom to the entrance hole (diameter: $30 \mathrm{~mm}$ ). In March of every year, old nest material was 
removed from all the nest boxes before the birds started nest building. Material remaining attached to the box walls was scraped off with a knife and a hard brush. Old nests containing fleas were kept as a source of fleas for the infestations.

The Great Tit is a small passerine bird common in woodlands, parks, and gardens of the Western Palearctic (Gosler 1993). During the breeding season, socially monogamous pairs defend a breeding territory, and nest in cavities or nest boxes. Hen fleas are common ectoparasites in our population. They migrate into the nests in spring, and their reproductive peak coincides with the breeding season of their hosts. Adult fleas feed on the blood of the breeding adults and their nestlings, they lay eggs in the nest material where the larvae develop, and form cocoons from which imago emerge after completion of development (details in Heeb et al. 1996, Tripet and Richner 1999). Blow fly larvae of the genus Protocalliphora are ectoparasites of young birds (Marshall 1981, Sabrosky et al. 1989). Every year, a proportion of nests in our population are infested by Protocalliphora flies (Heeb et al. 1996; P. Heeb, unpublished data). Adults are free-living flies that lay their eggs in the nest material, after the host eggs hatch (Gold and Dahlsten 1989). The fly larvae live in the nest material, and feed intermittently on chicks by sucking their blood. After a third larval stage they pupate in the nest material and emerge as imagos after the fledglings have left the nest (Gold and Dahlsten 1989, Bennett and Whitworth 1991, 1992, HurtrezBoussès et al. 1997).

\section{Experimental manipulations of flea infestations and nest humidity}

The experiment was performed in 1996. On the morning the birds laid their second egg, we weighed the nest fresh mass to the nearest $0.1 \mathrm{~g}$ with an electronic balance. Ectoparasites were then eliminated by heat-treating the nests (placed in a closed plastic bag) for 3 min using a microwave appliance fed by a portable $220-\mathrm{V}$ generator. The nests were left to cool after the heat treatment; they were sequentially assigned either to an "Infested" treatment $(N=79)$ and received 40 adult fleas, or were left "Uninfested" $(N=84)$. On the day after the whole clutch had been laid, nests were randomly assigned either to a "Dry" $(N=80)$, or a "Wet" treatment $(N=83)$. A flat piece of acrylic plastic $(2 \times 122 \times 122 \mathrm{~mm})$ was placed on the bottom of all nest boxes to increase the effectiveness of our treatments. Underneath the nests of the dry treatment we placed one 30-g bag of active silica gel (pink crystals, Fluka Chemie AG, Buchs, Switzerland) wrapped in absorbent paper. The bags were replaced on day 5 of incubation and on days 1, 5, 9, and 14 after hatching. The water removed by the silica gel bags was determined by their mass gain (precision $\pm 0.1 \mathrm{~g}$ ) between two visits. To control for any potential effect of the silicagel bags on the study organisms, we placed a $30-\mathrm{g}$ bag of inactive silica gel (blue crystals) wrapped in absorbent paper, underneath nests of the wet treatment. From a distance of $\sim 20 \mathrm{~cm}$, we then gently sprayed 1, 2 , or $3 \mathrm{~g}$ of stale tap water into a side of the nest material. The amount of water sprayed in each wet nest was adjusted to its fresh mass during egg laying (data from 1995 showed a positive correlation between nest fresh mass and the total amount of nest humidity, Pearson, $r=0.80, P<0.0001, N=83$ ). Water spraying was repeated on day 5 of incubation and on days 1,5 , 9, and 14 after hatching. This experiment resulted in four independent treatments where nest humidity and flea infestations were simultaneously manipulated, and all nests received the same number of visits. Birds in the four treatments did not differ significantly in laying date (Kruskal-Wallis test: $Z=0.11$, df $=3, P=0.99$ ), or clutch size (K-W: $Z=0.43$, df $=3, P=0.93$, Table $1)$. The fresh mass of the nests when the second egg was laid did not differ significantly between treatments $\left(F_{3,160}=1.55, P=0.20\right.$, Table 1$)$. The water treatments were repeated at regular intervals, and we expected that the humidity measured at the time of fledging reflected nest humidity during the breeding attempt of the birds. As expected, nests in the wet treatment were more humid than nests in the dry treatment $\left(F_{1,154}=6.63, P\right.$ $=0.01$, controlling for flea treatment, see Table 1).

\section{Assessment of ectoparasite loads}

Within $24 \mathrm{~h}$ after the last nestling in the brood fledged, the fresh mass of the nest was measured to the nearest $0.1 \mathrm{~g}$, and nests were placed in sealed plastic bags. Care was taken to count and recover all the flea cocoons attached to the nest box walls. The bags were then frozen at $-18^{\circ} \mathrm{C}$ and kept for later inspection. This procedure ensured that all ectoparasites present in the nest were killed within $24 \mathrm{~h}$ of their host becoming unavailable. The nest material was manually separated, and then thoroughly searched under a magnifying glass for adult fleas, flea larvae, and cocoons (flea larvae and cocoons are hereafter referred to jointly as "flea larvae"). Given the large number of breeding pairs in this study, and the amount of time it takes to count fleas, we randomly selected a subsample of 41 infested nests with similar laying dates and clutch sizes $(P>0.40)$ for detailed flea counts. To assess the prevalence (number of hosts infested) of new flea colonists to previously uninfested nests $(N=82)$, we determined the presence or absence of flea larvae in the nest material. Flea larvae in the uninfested treatments were produced by immigrant fleas that colonized the nests by horizontal transmission during the breeding attempt of the birds (Heeb et al. 1996). The prevalence and intensity (number of parasites in a host) of Protocalliphora infestations was determined by counting the larvae and pupae (hereafter referred to jointly as "pupae") in 158 nests. Protocalliphora species can only be determined at the adult stage; thus in the analyses we used the total counts (Gold and Dahlsten 1989, Bennett and Whitworth 
TABLE 1. Nest characteristics, breeding, and nestling growth parameters in a Great Tit population.

\begin{tabular}{|c|c|c|c|c|}
\hline \multirow[b]{2}{*}{ Variable } & \multicolumn{2}{|c|}{ Uninfested } & \multicolumn{2}{|c|}{ Flea-infested } \\
\hline & Dry & Wet & Dry & Wet \\
\hline \multicolumn{5}{|l|}{ Nest characteristics } \\
\hline Water manipulation $\dagger$ & $-47.8 \pm 0.5$ & $+13.7 \pm 0.5$ & $-48.7 \pm 0.6$ & $+12.6 \pm 0.5$ \\
\hline Fresh mass (2nd egg) (g) & $40.8 \pm 1.8$ & $45.6 \pm 2.5$ & $39.1 \pm 1.6$ & $42.3 \pm 2.1$ \\
\hline Total water $(\mathrm{g})$ & $12.3 \pm 1.0$ & $15.4 \pm 1.0$ & $16.3 \pm 1.1$ & $19.0 \pm 1.0$ \\
\hline Dry mass $(\mathrm{g})$ & $44.7 \pm 1.6$ & $48.0 \pm 2.3$ & $42.4 \pm 1.6$ & $43.4 \pm 2.0$ \\
\hline$N$ & 42 & 42 & 34 & 41 \\
\hline \multicolumn{5}{|l|}{ Breeding parameters } \\
\hline Laying date $\$$ & $21.6 \pm 0.8$ & $21.6 \pm 0.8$ & $21.4 \pm 0.8$ & $21.6 \pm 0.8$ \\
\hline Clutch size & $7.8 \pm 0.2$ & $7.6 \pm 0.2$ & $7.7 \pm 0.2$ & $7.7 \pm 0.2$ \\
\hline Brood size at hatching & $7.4 \pm 0.2$ & $7.1 \pm 0.2$ & $7.2 \pm 0.3$ & $7.3 \pm 0.2$ \\
\hline$N$ & $4 \overline{2}$ & $4 \overline{3}$ & 38 & $4 \overline{2}$ \\
\hline \multicolumn{5}{|l|}{ Nestling parameters } \\
\hline Tarsus length (mm) & $22.1 \pm 0.1$ & $22.0 \pm 0.1$ & $21.6 \pm 0.1$ & $21.8 \pm 0.1$ \\
\hline Wing length (mm) & $47.0 \pm 0.4$ & $47.8 \pm 0.5$ & $45.5 \pm 0.9$ & $46.0 \pm 0.8$ \\
\hline$N$ & $4 \overline{2}$ & 41 & $3 \overline{6}$ & 41 \\
\hline
\end{tabular}

Notes: Nests were either infested by fleas or were left uninfested, water was either removed (Dry) or added (Wet) in the nests (see Methods). $N$, numbers of nests. Means \pm SE are shown.

$\dagger$ Grams of water removed from $(-)$ or added to $(+)$ the nests.

$\ddagger 1=1$ April.

1991, 1992, Hurtrez-Boussès et al. 1997). Protocalliphora pupae probably had not enough time to emerge before nest collection, since no empty pupal cases were found (P. Heeb, personal observation). Other insects observed in the nests were a few small, undetermined dipteran larvae in one nest, and small detritivorous rove beetles in 10 nests (Family Staphylinidae). The small frequencies and numbers of other nest-dwelling insects are unlikely to have had a significant effect on our nest humidity treatments, or on host reproductive performance (Heeb et al. 1996).

\section{Quantification of nest humidity}

After the number of fleas and Protocalliphora pupae was determined, all the nests were dried in an oven at $80^{\circ} \mathrm{C}$ for $24 \mathrm{~h}$. The dry mass of the nests, a measure of nest size, was then determined to the nearest $0.1 \mathrm{~g}$. The total amount of water in the nests at the time of fledging was calculated by subtracting the dry mass from the fresh mass (Table 1). Nest humidity was determined as the total amount of water in the nests divided by nest dry mass (units: grams of water per grams of nest material). Nest materials used by our Great Tit population included moss, small roots, pine needles, deer hair, sheep wool, and rarely a feather. During the dissection of the nests we did not detect the presence of green plant material, or a change in the number of feathers in response to our treatments (P. Heeb, personal observation).

\section{Measures of Great Tit reproductive performance}

Nest boxes were checked at regular intervals before and during nest building to determine the start of egg laying. For each breeding pair we recorded the date when the first egg was laid, the clutch size, the date when incubation started, the date when the first egg hatched, and the number of young fledged. Fourteen days after hatching we measured nestling body mass (precision $\pm 0.1 \mathrm{~g}$ ), tarsus length $( \pm 0.1 \mathrm{~mm})$, and wing length $( \pm 1 \mathrm{~mm})$. Mean values for each brood were used as independent data points in the analyses. From day 16 after hatching onwards, the nests were inspected daily to determine when the last young fledged.

\section{Statistical analyses}

Analyses were performed using the Systat (Wilkinson 1989), JMP (Sall and Lehman 1996), and GLMStat (Beath 1997) statistical packages. Distributions of the flea counts, and some nest parameters, were normalized by square-root transformations, and analyzed with parametric statistics. Whenever transformations did not normalize the distribution of the data, the two-way ANOVA for ranked data, or the Poisson regression, were used to test the effects of the two experimental factors (Crawley 1993, Sokal and Rohlf 1995). All tests are two-tailed.

\section{RESULTS}

\section{The effect of flea infestations on nest humidity}

Humidity was higher in flea-infested than in uninfested nests (Fig. 2, $F_{1,154}=40.6, P<0.0001$, controlling for water treatment). There was no significant interaction between the flea and water treatment $(P=$ 0.79 ), suggesting that the effect of flea infestation on nest humidity was not affected by the water treatment. The dry mass of the nests tended to be smaller in fleainfested nests, but did not differ significantly in relation to water treatment (flea treatment: $F_{1,156}=3.26, P=$ 0.07; water treatment: $F_{1,156}=0.89, P=0.35$, Table 


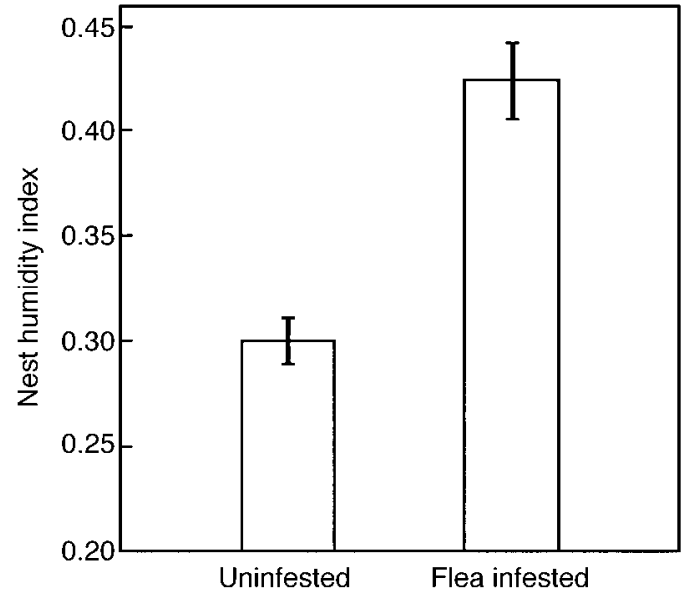

FIG. 2. Nest humidity index at fledging in relation to flea infestations. Great Tit nests were either infested by 40 adult fleas from egg laying onwards $(N=79)$ or were left unin fested $(N=84)$. Nest humidity as in Fig. 1 . Means $\pm 1 \mathrm{SE}$ shown.

1). Thus, experimental flea infestations caused an increase in nest humidity that was not associated with significant modifications of nest size.

\section{The effect of nest humidity on flea infestations, flea survival, and reproduction}

The frequency of infestations by flea immigrants in uninfested nests was higher in dry (32\%) than in wet (12\%) nests (log likelihood ratio: $\chi^{2}=5.20$, df $=1$, $P=0.02$, Table 2). In infested nests, the water treatments had no significant effect on the number of adult fleas (wet nests: $66 \pm 10$ fleas, mean \pm 1 sE, dry nests: $76 \pm 10$ fleas, $t$ test, $t=0.82$, df $=39, P=0.41)$, or on the number of flea larvae (wet nests: $1428 \pm 293$ larvae, dry nests: $1581 \pm 286$ larvae, $t$ test, $t=0.67$, df $=39, P=0.50)$. In a polynomial regression, we examined the contributions of nest size and humidity on flea numbers in infested nests (Table 3). As expected under the hypothesis that density-dependent competition among larvae affects their population size, the number of flea larvae tended to be positively correlated with nest dry mass. The number of flea adults and their larvae were positively correlated with nest humidity (Table 3). A visual inspection of the relationship between nest humidity and fleas suggests that both adult and larval numbers tended to decrease above a certain level of nest humidity (Fig. 3). Evidence for this decrease is provided by a significant second-order effect of nest humidity on flea numbers (Table 3).

\section{The effect of nest humidity and flea infestation on Great Tit reproduction}

An alteration of the harmful effect of flea infestation by nest humidity on host reproduction would be revealed by a significant interaction term between the
TAble 2. Frequencies of Protocalliphora and hen flea infestations in Great Tit nests. Nests were either infested by fleas or were left uninfested, and water was either removed (Dry) or added (Wet) to the nests (see Methods).

\begin{tabular}{lcclcc}
\hline \hline & \multicolumn{2}{c}{ Uninfested } & & \multicolumn{2}{c}{ Flea-infested } \\
\cline { 2 - 3 } \cline { 5 - 6 } Treatment & Dry & Wet & & Dry & Wet \\
\hline Protocalliphora & pupae & & & & \\
Absent & 28 & 34 & & 13 & 25 \\
Present & 13 & 8 & & 21 & 16 \\
$\quad$ No. pests & 41 & 42 & & 34 & 41 \\
Hen flea larvae & & & & & \\
Absent & 28 & 37 & & $\cdots$ & $\cdots$ \\
Present & 13 & 5 & & $\cdots$ & $\cdots$ \\
\hline
\end{tabular}

Note: Frequencies for flea larvae are shown for nests that were not experimentally infested by fleas (see Methods).

flea and water treatments. Brood size at hatching was not significantly different among birds in the different flea and water treatments (Table 1, two-way ANOVA for ranked data, flea treatment: $\chi^{2}=0.0014, P=0.97$, water treatment: $\left.\chi^{2}=0.26, P=0.61\right)$; the interaction between the two factors was not significant $(P>0.30)$. These results suggest that neither flea infestations nor the water treatment had a significant effect on the number of tit eggs hatching.

Flea infestations had a significant negative effect on nestling body mass, and tarsus and wing length. In contrast, the water treatment had no significant effect on nestling growth parameters (Fig. 4a, Tables 1 and 4). The interaction terms between flea and water treatment were all nonsignificant, suggesting that modifications of nest humidity did not alter the effect of fleas on nestling growth parameters (Table 4). Nestling body mass and tarsus length decreased with laying date and with increasing number of young in the brood (Table 4). Nestling wing length decreased with increasing number of young in the brood, and tended to decrease with laying date (Table 4). Significant interaction terms between flea treatment and either laying date or brood size would suggest a change in the harmful effect of the fleas on nestling growth in relation to the breeding conditions encountered by the birds. These interactions were all nonsignificant (Table 4), suggesting that the effect of the fleas on nestling growth did not vary during the birds' breeding season, or with the number of young in the brood.

TABLE 3. Analysis of flea numbers in relation to nest dry mass and amount of humidity within nests.

\begin{tabular}{lcccccccc}
\hline \hline \multirow{2}{*}{ Factor } & \multicolumn{3}{c}{ Adult fleas } & & \multicolumn{3}{c}{ Flea larvae } \\
\cline { 2 - 4 } \cline { 7 - 8 } \cline { 7 - 8 } & $F$ & df & $P$ & & $F$ & df & $P$ \\
\hline Dry mass & 0.17 & 1 & 0.68 & & 3.45 & 1 & 0.07 \\
Humidity & 7.36 & 1 & 0.01 & & 8.41 & 1 & 0.006 \\
(Humidity) $^{2}$ & 5.95 & 1 & 0.02 & & 5.48 & 1 & 0.02 \\
\hline
\end{tabular}

Note: The analyses were performed using a second-order polynomial on flea numbers (square-root transformed). 

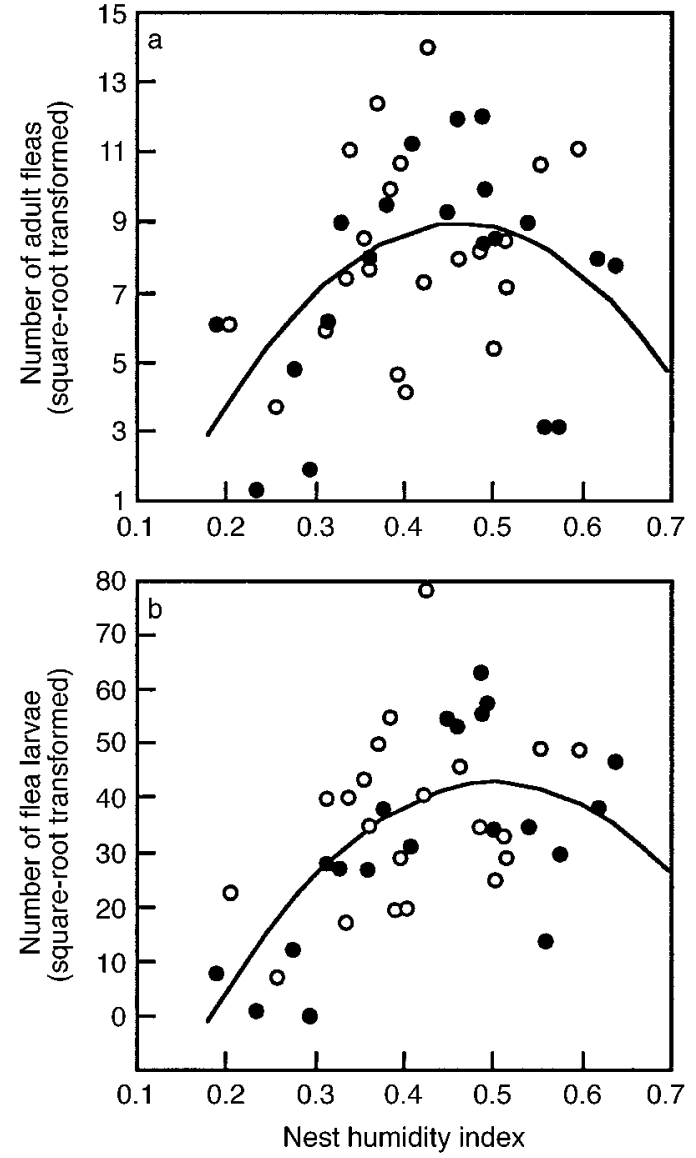

FIG. 3. The relationship between flea numbers and nest humidity index (see Fig. 1). In one treatment, water was removed from the nests (Dry nests, open circles; $N=21$ ); in the second treatment water was added to the nests (Wet nests, solid circles; $N=20$ ). The number of (a) adults fleas, and (b) flea larvae followed a significant quadratic relationship with nest humidity (see Table 3 ).

The number of young fledged per brood was analyzed using a Poisson regression with water and flea treatment as factors, and laying date and brood size as covariate. The minimal adequate model included flea treatment and laying date (scaled Pearson's $\chi^{2}: 165.9$, df $=162$, adjusted scale parameter: 1.02). Flea-infested nests fledged fewer young than uninfested nests (Fig. $4 \mathrm{~b}$, change in deviance, $\Delta D: 6.48, P=0.01$, df $=1$ ), and wet nests tended to fledge more young than dry nests (Fig. 4b, $\Delta D: 3.34, P=0.07$, df $=1$ ). The interaction term between flea and water treatment was not significant $(\Delta D: 1.04, P=0.31)$, suggesting that water treatment did not modify the effect of fleas on the number of young fledged (Fig. 4b). The number of young fledged decreased with laying date $(\Delta D: 19.54$, $P=0.0001, \mathrm{df}=1)$. The interactions of flea treatment with either laying date or brood size on the number of young fledged were both not significant $(P>0.15)$.
The effect of flea infestations and nest humidity on Protocalliphora infestations

The prevalence of Protocalliphora infestations in the nests was analyzed with nominal logistic regression including the flea and water treatment as factors. The prevalence of Protocalliphora infestations was significantly higher for Great Tits with infested (49\%) than uninfested $(25 \%)$ nests, and dry $(45 \%)$ than wet $(29 \%)$ nests (Table 2, flea treatment: $\chi^{2}=10.82$, df $=1, P$ $=0.001$, water treatment: $\chi^{2}=5.53$, df $=1, P=0.02$ ); the interaction between the two factors was not significant $(P=0.70)$. Among nests infested by at least one Protocalliphora pupa, the number of Protocalliphora pupae was lower in flea-infested than in uninfested nests (Fig. 5, two-way ANOVA for ranked data: $\left.\chi^{2}=14.20, \mathrm{df}=1, P=0.0002\right)$, but was not significantly affected by the water treatment $\left(\chi^{2}=1.45, P\right.$ $=0.23)$. The interaction between the water and flea treatment was not significant $(P>0.20)$. In conclusion, the prevalence of Protocalliphora infestations was higher, but the intensity lower, in flea-infested nests.

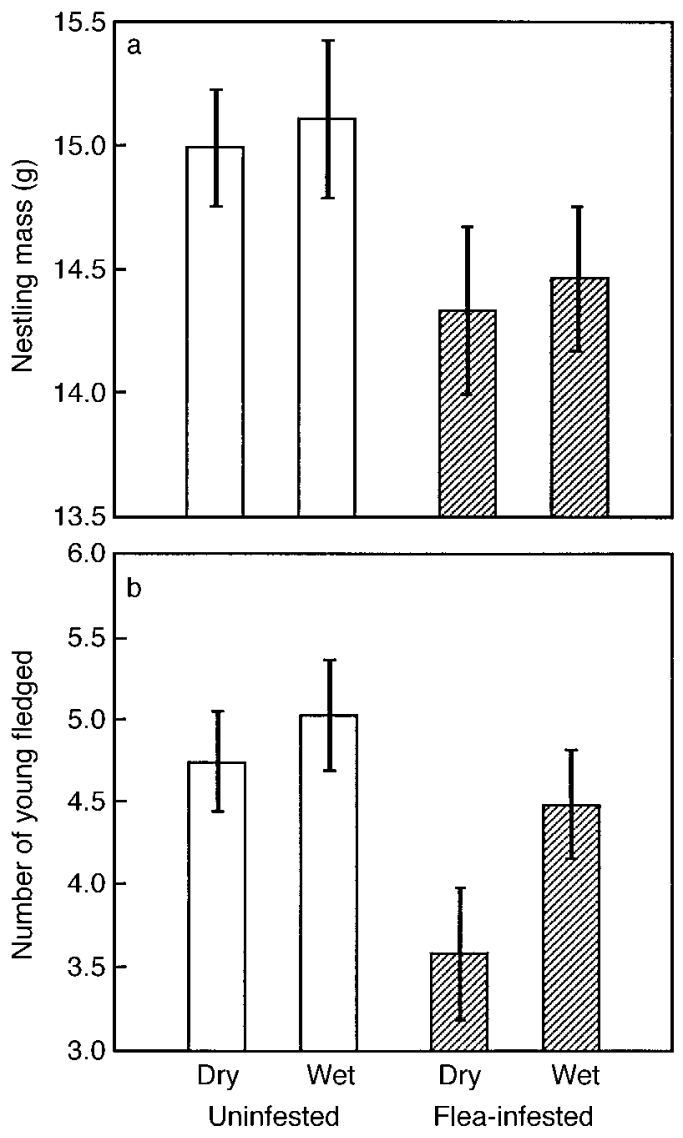

FIG. 4. The effect of hen fleas on Great Tit reproduction: (a) nestling mass $14 \mathrm{~d}$ after hatching and (b) number of young fledged. Nests were either infested by fleas or left uninfested, and water was either removed from nests (Dry) or added to nests (Wet). Means \pm 1 SE shown. 
TABLE 4. Analysis of nestling growth in relation to flea infestations and modifications of nest humidity.

\begin{tabular}{|c|c|c|c|c|c|c|}
\hline \multirow[b]{2}{*}{ Source } & \multicolumn{2}{|c|}{ Body mass } & \multicolumn{2}{|c|}{ Tarsus length } & \multicolumn{2}{|c|}{ Wing length } \\
\hline & $F$ & $P$ & $F$ & $P$ & $F$ & $P$ \\
\hline \multicolumn{7}{|l|}{ Factors } \\
\hline Flea treatment & 7.07 & 0.009 & 7.31 & 0.008 & 6.79 & 0.01 \\
\hline Water treatment & 0.24 & 0.63 & 0.29 & 0.59 & 0.76 & 0.38 \\
\hline Laying date & 7.40 & 0.007 & 4.40 & 0.04 & 2.99 & 0.09 \\
\hline Brood size & 25.27 & 0.0001 & 8.12 & 0.005 & 9.97 & 0.002 \\
\hline \multicolumn{7}{|l|}{ Interactions } \\
\hline Flea treatment $(\operatorname{trt}) \times$ Water trt & 0.34 & 0.56 & 1.64 & 0.20 & 0.02 & 0.88 \\
\hline Flea trt $\times$ Laying date & 0.99 & 0.32 & 0.001 & 0.97 & 1.02 & 0.31 \\
\hline Flea trt $\times$ Brood size & 0.48 & 0.49 & 0.02 & 0.88 & 0.30 & 0.59 \\
\hline
\end{tabular}

Notes: Nests were either infested by fleas or were left uninfested, and water was either added to or removed from the nests. Growth parameters were analyzed in a general linear model including the experimental treatments as factors with laying date and brood size as covariates. For all $F$ tests $\mathrm{df}=1,156$. All the other interactions between factors are not statistically significant.

The prevalence of Protocalliphora infestations was higher in dry nests.

\section{DISCUSSION}

\section{Nest humidity in relation to flea infestations}

The nest of cavity-breeding hosts provides the key habitat for the survival and reproduction of many ectoparasites (Rothschild and Clay 1952, Marshall 1981). It can be expected that nest properties affect the fitness of ectoparasites, and thus host-parasite coevolution. The present study is based on an earlier finding of a negative correlation between Great Tit nestling mass in flea-infested broods and nest humidity (Fig. 1). Here, we show experimentally a causal link between hen flea infestation and nest humidity (Fig. 2). Nest humidity is unlikely to have been affected by green plant materials or feathers, since Great Tits in our study population rarely use them in their nests (Heeb et al. 1996; P. Heeb, personal observation). Two mechanisms can potentially explain the presence of higher humidity in flea-infested nests. (1) Flea infestations can augment the energy expenditure of nestlings by increasing their

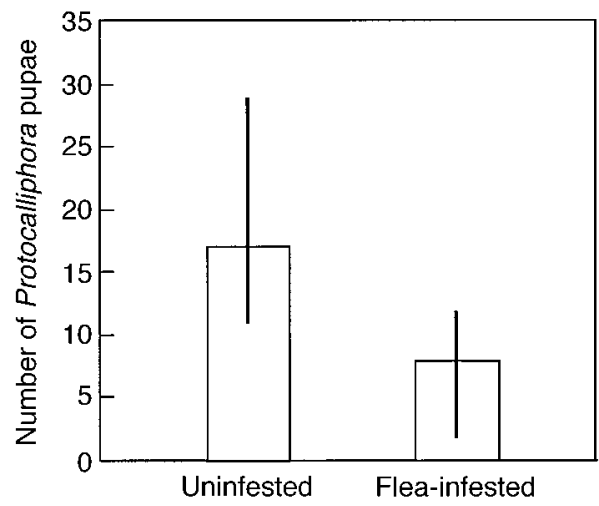

FIG. 5. Number of Protocalliphora pupae in Great Tit nests. Nests were either infested by fleas $(N=37)$ or left uninfested $(N=21)$. Median and interquartile ranges are shown. metabolism (Booth et al. 1993, Møller et al. 1994). A higher metabolism leads to greater evapotranspiration (Calder and King 1974, Dawson 1982), possibly increasing nest humidity. If total metabolic turnover increases with brood size, this should result in more evapotranspiration and higher nest humidity in larger broods. This suggestion is supported by a positive relationship between nest humidity and the number of young in the brood $\left(F_{1,154}=5.84, P=0.02\right.$, controlling for water and flea treatment). (2) The fleas' blood meal consists of $80 \%$ water, and fleas possess efficient morphological, physiological, and biochemical mechanisms for rapid water excretion (Rothschild and Clay 1952, Marshall 1987, Hinkle et al. 1991, Lehane 1991). The water excreted by adult hen fleas could thus add to nest humidity. The relative contribution of these two mechanisms to nest humidity remains unclear, and will require an assessment of the flea-induced changes in nestling metabolism, as well as the amounts of blood taken by adult fleas. Flea infestations resulted in greater nest humidity, and this effect can be considered as the first example of an ectoparasite acting as a physical ecosystem engineer (Thomas et al. 1998). As expected for physical ecosystem engineers, our results also suggest that physical modifications in the nests associated with flea infestations can affect the viability of other nest-dwelling organisms (Jones et al. 1997).

\section{The effect of nest humidity on flea infestation, survival, and reproduction}

Prevalence of immigrating fleas in nests of the uninfested treatment was higher in nests where we removed water than where we added water (Table 2). Interestingly, the prevalence of Protocalliphora was also higher in dry nests, suggesting a comparable effect of nest humidity on the colonizing ability of both ectoparasite species. Addition or removal of water in infested nests had no detectable effect on the number of adult fleas or larvae. This suggests that, within the range of humidity levels encountered by hen fleas in 
this study, modifications of nest humidity levels per se did not affect flea survival and reproduction. Tripet and Richner (1999) suggested that density-dependent competition among flea larvae is important in determining flea population sizes in Blue Tit nests. In agreement with their study, we found a tendency for a positive correlation between nest dry mass and the number of flea larvae.

Laboratory experiments have shown that water is an important abiotic factor for the successful emergence of hen fleas from cocoons, and for adult survival and longevity (Humphries 1966, 1967). In our study, flea numbers were positively correlated with nest humidity up to a certain level, above which flea numbers decreased (Fig. 3). Our results suggest that low levels of humidity could result in reduced flea survival and reproduction, leading to low infestation levels as found in open nests (Tripet and Richner 1997a). Natural nesting cavities used by Great Tits have been found to be susceptible to flooding, and could thus be significantly wetter than nest boxes (East and Perrins 1988). High nest humidity in natural cavities could modify the coevolutionary outcome of Great Tit-hen flea interactions through its negative effect on flea survival and reproduction. Future studies should determine experimentally whether there are different optimal humidity levels for vertebrate and invertebrate cavity-dwelling organisms, and examine which ecological factors are responsible for among-nest humidity variation.

\section{Effects of nest humidity and flea infestations on host reproductive performance}

Hen flea infestations significantly reduced nestling body mass, tarsus and wing length, and the number of young fledged by the hosts (Table 4, Fig. 4). Modifications of nest humidity had no detectable influence on the effect of fleas, as shown by the nonsignificant interactions between flea and water treatments on host reproductive parameters. Also, the harmful effect of hen fleas did not increase in relation to the seasonal decrease in the birds' reproductive performance, or with the number of young in the brood (Table 4). Undernourished or weak individuals, in general, are more affected by parasites (Marshall 1981, Gershwin et al. 1985), and it has been proposed that a deterioration in environmental conditions during breeding leads to an increase in the detrimental effects of ectoparasites (de Lope et al. 1993, Møller 1994a). In the House Martin, Delichon urbica, no significant brood reduction occurred after infestation of first broods with the house martin bug, Oeciacus hirundinis, as compared to uninfested broods, but significant brood reduction took place in infested second broods (de Lope et al. 1993). It was suggested that these results provide evidence for an increase in the negative effect of the bugs late in the season, when conditions for reproduction were more inadequate. However, nestlings in infested and reduced second broods had similar body masses to nest- lings of uninfested broods (de Lope et al. 1993), suggesting that, within the general trade-off between offspring quality and number, parents with infested nests put a relatively higher premium on nestling quality than on number (Richner and Heeb 1995). In our study, the number of adult fleas or their larvae did not vary significantly during the birds' breeding season (adult fleas: $F_{1,38}=0.26, P=0.61$; flea larvae: $F_{1,38}=0.68, P=$ 0.41 , controlling for water treatment), whereas nestling quality and the number young fledged by the birds decreased during the season. In this study, the nonsignificant interactions between season, brood size, and flea infestations (Table 4), do not provide evidence for a stronger effect of hen fleas with a seasonal deterioration in breeding conditions, or with an increasing number of nestlings in the brood.

In a series of papers, Møller (1989, 1992, 1994b) cautioned that high reproductive performance in bird populations breeding in nest boxes could be an artifact, and that generalizations based on these studies could be flawed. Møller suggested that lower predation rates, high breeding densities, and the habit of researchers to reduce natural ectoparasite levels by cleaning nest boxes could lead to incorrect interpretations of the birds' life histories, population dynamics, and ecology. In a reply, Koenig et al. (1992) argued that there is no a priori reason to consider the behavior of birds in nest boxes to be maladaptive, and that nest boxes offer possibilities for experimentation unavailable when working with natural cavities. Recent studies compared the reproductive performance of birds in natural cavities and nest boxes, and found that differences in reproductive success among them are not always clear (Robertson and Rendell 1990, review in Purcell et al. 1997). A general problem of studies comparing the reproductive success of birds breeding in nest boxes or natural cavities is that the choice of nest site is left to the birds, which might differ in their phenotypic traits and reproductive ability (Purcell et al. 1997). One way to determine the effect of the biases suggested by Møller on the evolution of bird life histories would be to experimentally randomize birds breeding in the two types of nesting cavities, and then determine their reproductive performances.

Our preliminary observations suggested that high nest humidity would have a detrimental effect on nestling growth (Fig. 1). Intriguingly, in this study we found that the number of fledglings tended to be higher in nests where we increased humidity levels (Fig. 4). This result could be expected if cavity-nesting birds are adapted to grow and reproduce in natural cavities where humidity levels can be higher than in nest boxes (East and Perrins 1988). Furthermore, high humidity levels in ectoparasite-infested nests could benefit the birds by reducing parasite survival and reproduction (as shown in Fig. 3). Our results suggest that future studies of bird-ectoparasite interactions should con- 
sider the role of nest humidity levels on bird reproductive performance.

\section{The effects of flea infestations and nest humidity on Protocalliphora infestations}

Nest humidity influenced the prevalence of both Protocalliphora and hen flea infestations. Nests where water was removed were more likely to be infested by the two ectoparasite species than nests where water was added (Table 2). A large body of literature exists on the prevalence and intensity of infestations by fleas and Protocalliphora flies in birds' nests (for reviews see Sabrosky et al. 1989, Bennett and Whitworth 1991, 1992, Johnson and Albrecht 1993, Tripet and Richner 1997a). However, observational data are of limited value for determining the key factors shaping infestation patterns, and the structure of parasite communities within hosts (Simberloff and Moore 1997, Poulin 1998). Successful infestation requires three main steps; (1) the parasite has to find a suitable host, (2) it has to settle on the host and lay eggs, and (3) the offspring produced by the parasite have to survive and reach the larval or pupal stage (Combes 1991). Hen flea immigration into uninfested nests, and Protocalliphora infestations in all nests, were detected after the nestlings fledged, and our data does not allow us to determine at which step the differences between treatments arose. Higher infestation prevalence in dry nests by both hen fleas and Protocalliphora could have resulted from female ectoparasites preferring to lay eggs in them. Alternatively, infestation by female parasites may have been random in relation to the water treatment, and lower ectoparasite survival and/or reproductive success in wet nests could have reduced their infestation prevalence.

We found that the prevalence of Protocalliphora infestations was higher in nests experimentally infested by fleas (Table 2). These differences are likely to arise after the bird eggs have hatched, since adult Protocalliphora parasitize their hosts when the parents are feeding the young (Gold and Dahlsten 1989, HurtrezBoussès et al. 1997). Ectoparasitic dipterans are known to use chemical (e.g., $\mathrm{CO}_{2}$ ), and visual cues to locate their hosts (Gold and Dahlsten 1989, Lehane 1991). Higher begging rates of Great Tit nestlings in fleainfested nests (Christe et al. 1996b) could lead to an increase in their metabolism (Booth et al. 1993, Møller et al. 1994), resulting in greater amounts of $\mathrm{CO}_{2}$ being emitted from infested broods. Alternatively, Protocalliphora females could be attracted by an increase in food provisioning rates at infested nests, as shown for male Great Tits and parent Blue Tits (Christe et al. 1996b, Tripet and Richner 1997b). Unpublished data from two previous years for infested and uninfested broods in our population revealed that parent Great Tits did not increase their provisioning rate in response to flea infestations (males: $F_{1,126}=0.12, P=0.73$, females: $F_{1,127}=0.68, P=0.41$, controlling for year and brood size). In contrast, our data showed that flea infestation reduced the hematocrit (amount of red cells in the blood) of nestlings $\left(F_{1,186}=20.7, P<0.0001\right.$, controlling for year and brood size). Thus, in our population, flea-infested broods might have produced stronger olfactory cues due to a change in nestling metabolism, and could be easier to locate by Protocalliphora flies than uninfested broods.

The intensity of Protocalliphora infestations was lower in nests experimentally infested by fleas, suggesting the existence of a negative interaction between hen fleas and Protocalliphora in Great Tit nests (Fig. 5). A number of nonexclusive mechanisms can explain this negative association. (1) The immune responses mounted by Great Tit nestlings against the fleas could reduce the viability of Protocalliphora larvae (Baron and Weintraub 1987, Devaney and Augustine 1988, de Lope et al. 1998). (2) High humidity levels in fleainfested nests could have decreased the survival of Protocalliphora larvae (Bennett and Whitworth 1991). As suggested by Thomas et al. (1998), for the action of parasites as physical ecosystem engineers, modifications in the physical properties of nests by fleas could have a significant effect on infestation intensities by Protocalliphora. (3) Protocalliphora larvae are bigger, and less mobile, than adult fleas, and could suffer from higher mortality rates due to increased nest sanitation behavior by female Great Tits in flea-infested nests (Christe et al. 1996a). In our study, there was a tendency for female Great Tits with flea-infested nests to build smaller nests that could have also reduced the survival probability of Protocalliphora larvae. (4) Depending on the type of competition between hen flea and Protocalliphora larvae, female Protocalliphora could have laid fewer eggs in flea-infested nests (Ives 1989). The negative association between the two ectoparasites suggests that hen fleas could impose selection pressures on the evolution of Protocalliphora life history traits. Future studies should determine the mechanisms underlying the negative association between hen flea and Protocalliphora larvae. The existence of a quantifiable interspecific association among these two ectoparasites provides a suitable system to study the roles of abiotic factors and interspecific competition in shaping parasite infracommunity structure (Poulin 1998). As far as we are aware, this study is the first to show experimentally that a modification of an abiotic factor changed the infestation prevalence of two ectoparasites. It also provides the first experimental demonstration of an interspecific association between two ectoparasite species. Great Tit nests experimentally infested with hen fleas had, on the one hand, a higher prevalence and, on the other hand, a lower intensity of Protocalliphora infestations.

\section{ACKNOWLEDGMENTS}

We gratefully acknowledge A. Roulin, M. G. W Brinkhof, and two anonymous referees for comments. Financial support 
was provided by the Swiss National Science Foundation, grant Number 31-43570.95 (to H. Richner).

\section{LITERATURE CITED}

Baron, R. W., and J. Weintraub. 1987. Immunological responses to parasitic arthropods. Parasitology Today 3:7782.

Beath, K. J. 1997. GLMStat user manual version 3.1. Beath, Sydney, Australia.

Behnke, J. M., C. J. Barnard, and D. Wakelin. 1992. Understanding chronic nematode infections: evolutionary considerations, current hypotheses and the way forward. International Journal of Parasitology 22:861-907.

Bennett, G. F., and T. L. Whitworth. 1991. Studies on the life history of some species of Protocalliphora (Diptera: Calliphoridae). Canadian Journal of Zoology 69:20482058.

Bennett, G. F., and T. L. Whitworth. 1992. Host, nest, and ecological relationships of species of Protocalliphora (Diptera: Calliphoridae). Canadian Journal of Zoology 70:5161.

Booth, D. T., D. H. Clayton, and B. A. Block. 1993. Experimental demonstration of the energetic cost of parasitism in free-ranging hosts. Proceedings of the Royal Society of London B. 253:125-129.

Brown, C. R., and M. B. Brown. 1986. Ectoparasitism as a cost of coloniality in Cliff Swallows (Hirundo rustica). Ecology 67:1206-1218.

Bull, J. J. 1994. Virulence. Evolution 48:1423-1437.

Butler, J. M., and T. J. Roper. 1996. Ectoparasites and sett use in European badgers. Animal Behaviour 52:621-629.

Calder, W. A., and J. R. King. 1974. Thermal and caloric relations of birds. Pages 259-413 in D. S. Farner and K C. Parkes, editors. Avian Biology (Volume 4). Academic Press, New York, New York, USA.

Christe, P., A. Oppliger, and H. Richner. 1994. Ectoparasite affects choice and use of roost sites in the Great Tit, Parus major. Animal Behaviour 47:895-898.

Christe, P., H. Richner, and A. Oppliger. 1996a. Of Great Tits and fleas: sleep baby sleep. . . Animal Behaviour 52: 1087-1092.

Christe, P., H. Richner, and A. Oppliger. 1996b. Begging, food provisioning, and nestling competition in Great Tit broods infested with ectoparasites. Behavioral Ecology 7: 127-131.

Clark, L. 1990. Starlings as herbalists: countering parasites and pathogens. Parasitology Today 6:358-360.

Combes, C. 1991. Ethological aspects of parasite transmission. American Naturalist 138:866-880.

Crawley, M. J. 1993. GLIM for ecologists. Blackwell Science, Oxford, UK.

Dawson, W. R. 1982. Evaporative losses of water in birds. Comparative Biochemistry and Physiology. Comparative Physiology 71:495-509.

de Lope, F., G. González, J. J. Pérez, and A. P. Møller. 1993. Increased detrimental effects of ectoparasites on their bird hosts during adverse environmental conditions. Oecologia 95:234-240.

de Lope, F., A. P. Møller, and C. de la Cruz. 1998. Parasitism, immune response and reproductive success in the house martin Delichon urbica. Oecologia 114:188-193.

Devaney, J. A., and P. C. Augustine. 1988. Correlation of estimated and actual northern fowl mite population with the evolution of specific antibody to a low molecular weight polypeptide in sera of infested hen. Poultry Science 67: 549-556.

Dumbacher, J. P., and S. Pruett-Jones. 1996. Avian chemical defense. Current Ornithology 13:137-174.

East, M. L., and C. M. Perrins. 1988. The effect of nestboxes on breeding populations of birds in broadleaved temperate woodlands. Ibis 130:393-401.
Ebert, D. 1994. Virulence and local adaptation of a horizontally transmitted parasite. Science 265:1084-1086.

Ebert, D. 1998. The evolution and expression of virulence. In S. C. Stearns, editor. The evolution of health and disease. Oxford University Press, Oxford, UK.

Ebert, D., and E. A. Herre. 1996. The evolution of parasitic diseases. Parasitology Today 12:96-101.

Eeva, T., E. Lehikoinen, and J. Nurmi. 1994. Effects of ectoparasites on breeding success of Great Tits (Parus major) and Pied Flycatchers (Ficedula hypoleuca) in an air pollution gradient. Canadian Journal of Zoology 72:624-635.

Frank, S. 1991. Ecological and genetic models of host-pathogen coevolution. Heredity 67:73-83.

Frank, S. 1996. Models of parasite virulence. Quarterly Review of Biology 71:37-78.

Gershwin, M. E., R. S. Beach, and L. S. Hurley. 1985. Nutrition and immunity. Academic Press, London, UK.

Goater, C. P., and J. C. Holmes. 1997. Parasite-mediated natural selection. Pages 9-29 in D. H. Clayton and J. Moore, editors. Host-parasite evolution: general principles and avian models. Oxford University Press, Oxford, UK.

Gold, C. S., and D. L. Dahlsten. 1989. Prevalence, habitat selection and biology of Protocalliphora (Diptera: Calliphoridae) found in nests of mountain and chestnut-backed chickadees in California. Hilgardia 57:1-19.

Gosler, A. 1993. The Great Tit. Hamlyn, London, UK.

Harper, G. H., A. Marchant, and D. G. Boddington. 1992. The ecology of the hen flea Ceratophyllus gallinae and the moorhen flea Dasypsyllus gallinulae in nest boxes. Journal of Animal Ecology 61:317-327.

Hart, B. L. 1997. Behavioural defence. Pages 59-77 in D. H. Clayton and J. Moore, editors. Host-parasite evolution: general principles and avian model. Oxford University Press, Oxford, UK.

Heeb, P., I. Werner, M. Kölliker, and H. Richner. 1998. Benefits of induced host responses against an ectoparasite. Proceedings of the Royal Society of London Series B. 265: $51-56$.

Heeb, P., I. Werner, H. Richner, and M. Kölliker. 1996. Horizontal transmission and reproductive rates of hen fleas in Great Tit nests. Journal of Animal Ecology 65:474-484.

Hinkle, N. C., P. G. Koehler, and W. H. Kern Jr. 1991. Hematophagous strategies of the cat flea (Siphonaptera: $\mathrm{Pu}$ licidae). Florida Entomologist 74:377-385.

Humphries, D. A. 1966. Drinking of water by fleas. Entomologist's Monthly Magazine 102:260-262.

Humphries, D. A. 1967. Uptake of atmospheric water by the hen flea Ceratophyllus gallinae (Schrank). Nature 214:426.

Hurtrez-Boussès, S., J. Blondel, P. Perret, and F. Renaud. 1997. High blow fly parasitic loads affect breeding success in a mediterranean population of blue tits. Oecologia 112: $514-517$.

Ives, A. R. 1989. The optimal clutch size of insects when many females oviposit per patch. American Naturalist 133: 671-687.

Johnson, L. S., and D. J. Albrecht. 1993. Effects of haematophagous ectoparasites on nestling house wrens: who pays the cost of parasitism? Oikos 66:255-262.

Jones, C. G., J. H. Lawton, and M. Shachak. 1997. Positive and negative effects of organisms as physical ecosystem engineers. Ecology 78:1946-1957.

Koenig, W. D., P. A. Gowaty, and J. L. Dickinson. 1992. Boxes, barns, and bridges: confounding factors or exceptional opportunities in ecological studies? Oikos 63:305308.

Lee, P. L. M., and D. H. Clayton. 1995. Population biology of swift (Apus apus) ectoparasites in relation to host reproductive success. Ecological Entomology 20:43-50.

Lehane, M. J. 1991. Biology of blood-sucking insects. Harper Collins, London, UK. 
Lehmann, T. 1993. Ectoparasites: direct impact on host fitness. Parasitology Today 9:8-13.

Lipsitch, M., and E. R. Moxon. 1997. Virulence and transmissibility of pathogens: what is the relationship? Trends in Microbiology 31:31-37.

Marshall, A. G. 1981. The ecology of ectoparasitic insects. Academic Press, London, UK.

Marshall, A. G. 1987. Nutritional ecology of ectoparasitic insects. Pages 721-739 in F. Slansky and J. G. Rodriguez, editors. Nutritional ecology of insects, mites, spiders and related invertebrates. John Wiley and Sons, New York, New York, USA.

Møller, A. P. 1989. Parasites, predators and nest boxes: facts and artefacts in nest box studies of birds? Oikos 56:421423.

Møller, A. P. 1992. Nest boxes and the scientific rigour of experimental studies. Oikos 63:309-311.

Møller, A. P. 1994a. Parasites as an environmental component of reproduction in birds as exemplified by the swallow. Ardea 82:161-172.

Møller, A. P. 1994b. Facts and artefacts in nest-box studies: implications for studies of birds of prey. Journal of Raptor Research 28:143-148.

Møller, A. P. 1997. Parasitism and the evolution of host life history. Pages 105-127 in D. H. Clayton and J. Moore, editors. Host-parasite evolution: general principles and avian models. Oxford University Press, Oxford, UK.

Møller, A. P., K. Allander, and R. Dufva. 1990. Fitness effects of parasites on passerine birds: a review. Pages 269-280 in J. Blondel, A. Gosler, J. D. Lebreton, and R. H. McCleery, editors. Population biology of passerine birds: an integrated approach. NATO series G24, Springer-Verlag, Berlin, Germany.

Møller, A. P., F. de Lope, J. Moreno, G. González, and J. J. Pérez. 1994. Ectoparasites and host energetics: house martin bugs and house martin nestlings. Oecologia 98:263268.

Møller, A. P., and J. Erritzøe. 1996. Parasite virulence and host immune defense: host immune response is related to nest reuse in birds. Evolution 50:2066-2072.

Oppliger, A., H. Richner, and P. Christe. 1994. Effect of an ectoparasite on lay date, nest-site choice, desertion, and hatching success in the Great Tit (Parus major). Behavioral Ecology 5:130-134.

Pacejka, A. J., C. M. Gratton, and C. F. Thompson. 1998. Do potentially virulent mites affect House Wren (Troglodytes aedon) reproductive success? Ecology 79:1797-1806.

Poulin, R. 1998. Evolutionary ecology of parasites: from individuals to communities. Chapman and Hall, London, UK.
Purcell, K. L., J. Verner, and L. W. Oring. 1997. A comparison of the breeding ecology of birds nesting in boxes and tree cavities. Auk 114:646-656.

Read, A. F. 1994. The evolution of virulence. Trends in Microbiology 2:73-76.

Richner, H., and P. Heeb. 1995. Are clutch and brood size patterns in birds shaped by ectoparasites? Oikos 73:435441.

Richner, H., A. Oppliger, and P. Christe. 1993. Effect of an ectoparasite on reproduction in Great Tits. Journal of Animal Ecology 62:703-710.

Robertson, R. J., and W. B. Rendell. 1990. A comparison of the breeding ecology of a secondary cavity nesting bird, the tree swallow (Tachycineta bicolor), in nest boxes and natural cavities. Canadian Journal of Zoology 68:10461052.

Rothschild, M., and T. Clay. 1952. Fleas, flukes, and cuckoos. Collins, London, UK.

Sabrosky, C. W., G. F. Bennett, and T. L. Whitworth. 1989. Bird blow flies (Protocalliphora) in North America (Diptera: Calliphoridae) with notes on the Palaearctic species. Smithsonian Institution Press, Washington, D.C., USA.

Sall, J., and A. Lehman. 1996. JMP Start Statistics. A guide to statistics and data analysis using JMP and JMP IN software. Duxbury Press, Belmont, California, USA.

Simberloff, D., and J. Moore. 1997. Community ecology of parasites and free-living animals. Pages 59-77 in D. H. Clayton and J. Moore, editors. Host-parasite evolution: general principles and avian models. Oxford University Press, Oxford, UK.

Sokal, R. R., and F. J. Rohlf. 1995. Biometry. Third edition. Freeman, New York, New York, USA.

Thomas, F., R. Poulin, T. de Meeüs, J. F. Guégan, and F. Renaud. 1998. Parasites and ecosystem engineering: what roles could they play? Oikos 84:167-171.

Tripet, F., and H. Richner. 1997a. The coevolutionary potential of a "generalist" parasite. Parasitology 115:419427.

Tripet, F., and H. Richner. 1997b. Host responses to ectoparasites: food compensation by parent blue tits. Oikos 78: 557-561.

Tripet, F., and H. Richner. 1999. Density-dependent processes in the population dynamics of a bird ectoparasite Ceratophyllus gallinae. Ecology 80:1267-1277.

Wakelin, D. 1996. Immunity to parasites. Second edition. Cambridge University Press, Cambridge, UK.

Wilkinson, L. 1992. SYSTAT: The system for statistics. SYSTAT, Evanston, Illinois, USA.

Winkler, D. W. 1993. Use and importance of feathers as nest lining in tree swallows (Tachycineta bicolor). Auk 110:2936. 